\title{
Competitiveness of Small-Medium, New Generation Reactors: a Comparative Study on Decommissioning (ICONE17 - 75254)
}

\author{
Giorgio Locatelli \\ Politecnico di Milano, \\ Dept. Management, Economics and Industrial \\ Engineering \\ Milano, Italy
}

\author{
Mauro Mancini \\ Politecnico di Milano \\ Dept. Management, Economics and Industrial \\ Engineering \\ Milano, Italy
}

\begin{abstract}
Small medium reactors (SMR) are going to be an important player of the worldwide nuclear renaissance. The economy of scale plays against the development of this kind of reactors, even if sometimes its influence is overestimated so that SMR appears to have a Levelised Unit Electricity Cost (LUEC) significantly higher than Large Reactors (LR). However, the economy of scale applies only if the designs of SMR are similar to that of LR, but this is not the case, since the small size allows original design solutions not accessible to large size reactors. The literature already presents studies showing how, under certain assumptions, the Capital Cost and the Operation and Maintenance (O\&M) Cost of a site provided by one large reactor is quite similar to another site composed by 4 SMRs providing the same power. However the literature still lacks of this kind of analysis about the decommissioning cost. The paper fulfill this gap investigating the cost breakdown of a decommissioning project and providing a literature review about its cost estimate techniques and managerial approach.

The paper identifies and briefly discusses the different cost drivers related to the decommissioning phase of nuclear plant focusing the attention on those critical in the comparison between SMR and LR (economy of scale, multiple units in a single site, technical saving, decommissioning strategy -"immediate decommissioning" or "deferred decommissioning"). The IRIS reactor is used as the example of SMR to quantify the effect of these drivers, but the analysis and conclusions are applicable to the whole spectrum of new small nuclear plants. The results show that when all these factors are accounted for in a set of realistic and comparable configurations, and with the same power installed in the site, the decommissioning costs of SMR respect to LR drops from three times higher to two times. If more than 1 Large Reactor is considered the gap increases since also the Large Reactor investment reaps advantages from site sharing.
\end{abstract}

\section{Introduction}

\subsection{The SMRs and their economics}

Nowadays smaller size reactors are needed to fulfill the growing energy needs of developing countries and emerging markets. This has been identified within the US DOE Global Nuclear Energy Partnership (GNEP) initiative as one of the key elements, "GridAppropriate Reactors", needed to enable worldwide expansion of the peaceful use of nuclear power.

Smaller size reactors (IAEA defines "small" those reactors with power < $300 \mathrm{MWe}$ and "medium" with power $<700 \mathrm{MWe}$ ) are the logical choice for smaller countries or those with a limited electrical grid. Small reactors have attractive characteristics of simplicity, enhanced safety and require limited financial resources. However, they are not seen profitable because of the accepted axiom of the economy of scale which seems to rule the Capital Cost, O\&M and decommissioning cost. Carelli et al. [1] already show for Capital cost and O\&M that economy of scale applies only if the reactors have similar designs, as in the past. This is no longer true today, where small modular reactors have very different designs and characteristics from the large ones, so the LUEC for a smaller size reactor is not much higher than for a large size reactor (as often supposed). This paper continues the economics assessment of SMR vs. LR dealing with the decommissioning cost. The scope of this research project has been to investigate how the decommissioning cost increases in the comparison of two sites: one with 1 o 2 LR and the other with 4 or 8 SMR.

\subsection{Decommissioning cost and market considerations}

IAEA [2] declares that the scope of the work of a decommissioning project includes "Administrative and technical actions taken to allow the removal of some or all of the regulatory controls from a facility [...] The actions will need to be such as to ensure the long term protection of the public and the environment, and typically include reducing the levels of residual radionuclides in the materials and on the site of the facility so that the materials can be safely recycled, reused or disposed of as exempt waste or as radioactive waste and the site can be released for unrestricted use or otherwise reused.". 
Since decommissioning costs incurs after a nuclear power plant is shouted down, they should be estimated in a reliable way because transparent accounting principles should be applied to establish and maintain an adequate decommissioning fund. In nearly all countries, the operator/utility is responsible for the decommissioning costs. However, in cases where nuclear power plants are state-owned, the responsibilities may be distributed between the operator and the state as owner [3]. In the US, in order to finance the decommissioning project, almost all utility owners and licensees, historically, collected fees from their electricity customers over the life of the plant, and deposited these fees into separate funds managed by external financial managers [4]. A similar approach is followed in the majority of the countries.

Today's ageing facilities range from experimental plants from the " 50 s and the '60s to more modern power reactors. The World Nuclear Association Database (WNA) summarizes nuclear facilities which have been retired from operation and are either awaiting or undergoing decommissioning as:

- 115 power and research reactors;

- 5 reprocessing facilities;

- 14 fuel fabrication plants;

- 60 mines

The total worldwide decommissioning market is estimated at thousands of billions of dollars [5]. On the other hand the most recent studies, quoted in Table 1 , indicate as the decommissioning cost represents a small percentage of the LUEC. This is due to the fact that the Present Value of a cost that will be incurred within 4070 years it is much lower than its not-actualised value. Beside this fact it must be remembered that the notactualised value of a Decommissioning project is around 400-500 $\$ / \mathrm{KWe}$ [3], whereas, for a reference of the same year, the construction project has a capital cost of around 2000-2100 \$/KWe ([6], Table 49). Therefore it is necessary to careful estimate this cost.

\begin{tabular}{|l|l|}
\hline Williams et Miller, 2006 & $0.84 \%$ \\
\hline Gallanti et Parozzi, 2006 & $4 \%$ \\
\hline NERA study 2004 & $1-5 \%$ \\
\hline
\end{tabular}

Table 1 Decommissioning cost impact on LUEC according to various studies [1]

\section{Literature review: cost Structure quantification}

The international literature proposes just one Decommissioning Cost Breakdown Structure (CBS) accepted worldwide. It has been provided by NEA [7] and divides the Decommissioning Cost in 11 main areas (Table 2) and three levels of detail.

\begin{tabular}{|c|l|}
\hline $\begin{array}{c}\text { Element } \\
\text { Code }\end{array}$ & Element name \\
\hline 01 & Pre-decommissioning actions \\
\hline 02 & Facility shutdown activities \\
\hline 03 & Procurement of general equipment \\
\hline 04 & Dismantling activities \\
\hline 05 & Waste processing, storage and disposal \\
\hline 06 & $\begin{array}{l}\text { Site security, surveillance and } \\
\text { maintenance }\end{array}$ \\
\hline 07 & Site restoration, cleanup and landscaping \\
\hline 08 & Project management \\
\hline 09 & Research and development \\
\hline 10 & Fuel and nuclear material \\
\hline 11 & Other costs \\
\hline
\end{tabular}

Table 2 Standardised cost items for decommissioning projects [7]

Since different project stages require different inputs and outputs [8] beside the CBS in table 2 there are many approaches to quantify the absolute value of the Decommissioning Cost. Therefore the international literature presents different approaches dealing with decommissioning cost that can be divided in:

- References providing guidelines and methodologies, without a detailed cost estimation

- References providing detailed cost estimation

\subsection{References without detailed cost estimation}

IAEA provides also a general overview of the financial aspect [9] providing useful guidelines to reduce the decommissioning cost. However this document alone cannot give an estimation of the Decommissioning cost. A similar approach is reflected in other IAEA document [10-12].

KwanSeong et al. [13] propose the computation of the decommissioning cost with a methodology where cost items are used as cost variables by adopting the method of parametric cost estimating. The advantage of parametric cost estimating is to use cost drivers like units and items as factors. This methodology require too many specific detail, therefore it cannot be used to compute a general value.

Manning and Gilmour [14] propos an estimating methodology and computer-based application called 
"the PRICE system". This approach is based on a database which holds resource demand data on a comprehensive range of decommissioning activities. This data is used in conjunction with project specific information (the quantities of specific components) to produce decommissioning cost estimates.

\subsection{References providing detailed cost estimation}

NEA and OECD [3] present the decommissioning cost estimation of many reactors considering the "boundary conditions" as country, technology, decommissioning type and so on.

The estimation of decommissioning costs of a WWER440 nuclear power plants in many countries is given by IAEA [15] and regards Armenia, Bulgaria, Czech Republic, Finland, Germany, Hungary, Russian Federation, Slovakia and Ukraine. This TEC-DOC has been used to calculate the technical saving presented in chapter 4.2.

Pittiglio [16] provides a very useful reference to estimate the cost of a generic PWR or BWR reactor and, under certain hypothesis, this reference has been used to develop this study as described in chapter 4. It provides also the disbursement curve of a decommissioning project.

Detailed information about the decommissioning cost of large Reactor (ABWR ACR-700 AP1000 ESBWR), can be found in [17] however does not do the same with SMR.

The Radioactive Waste Management, Nirex [18], working with Committee on Radioactive Waste Management (CoRWM) presents the result of two studies about the cost and timing of two different strategies to manage Radioactive Waste: Deep Geological Disposal and Phased Deep Geological Disposal. Phased Deep Geological Disposal is the same process as deep disposal, but would allow to keep monitoring and later retrieval of the waste. The latter option was favoured by the public, because of its ability to retrieve the waste and dispose of it in a more permanent and safe manner at a later date.

Even if the literature is rich of different approaches these methodologies cannot be implemented "as-theyare" if the scope is to find the differential decommissioning cost. With the information available at this project stage it is not possible to go through a bottom up approach, therefore the model follows a topdown estimation. The proposed model considers the advantage coming from the site sharing and the technological solutions embedded in the SMR design (which represent the real technological breakthrough) and the disadvantage coming from the economy of scale.

\section{The model}

\subsection{Quantification approach}

Since the scope is to compute the differential decommissioning cost it is not possible to use the literature about decommissioning cost "as-is" since its goal is to compute the absolute cost of a decommissioning project. Instead the relative cost LR vs. SMR can be computed by using the methodology presented by Kuznetsov [19] and Carelli [1].

According to this approach the comparison between LR and SMR is done using cost drivers instead of absolute values.

This cost model assumes the specific cost for the Large Reactor, in terms of $\$ / \mathrm{KWe}$, equal to one, then computes a relative number for the SMR. Considering the economy of scale the SMR has a specific cost greater than one (see arrow 1 in Figure 1), however beside the economy of scale there are some factors -i.e. cost drivers - able to reduce the gap. By multiplying these values, one greater than 1 and some other smaller than 1, it is possible to compute the final ratio $\frac{\text { SMR cost }}{\text { LR cost }}$

The model aims to compare a generic LR (1340 MWe) with a number of SMR able to provide the same power installed. IRIS has been chose as SMR reference design; however the methodology applies for any other SMR design. Considering the "same power" constraint (because this value is imposed by the market) and the IRIS size (335 MWe) the model compares 1 LR vs. 4 IRIS or 2LR vs. 8 IRIS.

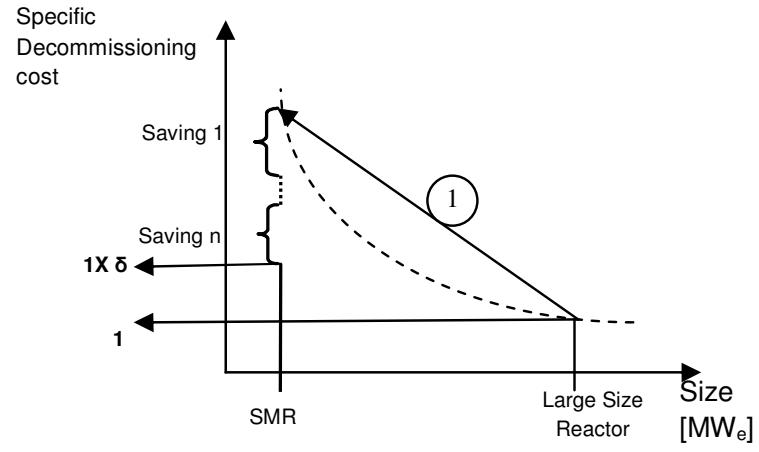

Figure 1 Structure of the model 


\subsection{Cost Drivers}

Following the approach presented in the mentioned papers it is now necessary to identify the differential cost drivers for the decommissioning cost of four SMR respect to a LR. The [3] is the worldwide reference for the analysis of decommissioning cost for nuclear reactors and provides a complete list of all the cost drivers able to impact on a decommissioning project. In order to determine which ones are differential in this analysis, each cost driver is analyzed in the following paragraphs; Table 3 summaries the results of this analysis. It is important to highlight that the purpose (at this level of the analysis) is to identify the most relevant cost drivers suitable for a further evaluation using public data nowadays available, without focusing on a particular country or a specific design.

\section{Size of reactor}

The size of the reactor is correlated to the economy of scale. There is a clear evidence of the economy of scale [3] as detailed in chapter 4 . The size of the reactors is correlated to the amount and nature of the radioactive waste, that is, the levels of radioactivity remaining in reactor materials at the end-of-life. Since some of the cost in the decommissioning process does not depend on the reactor size (or the dependency it is very weak, for instance Site security, surveillance and maintenance or Project management) increasing the size of the reactor decreases the specific cost $[\$ / \mathrm{KWe}]$.

\section{Number of units on the site}

According to IAEA [9] single unit sites have to bear the entire burden of costs: facility, craft workers, management costs and so on. The single unit with no sharing of on-site expertise or experience (i.e. there is not learning economies) tends to have a high cost. This cost driver has been quantified in chapter 4.1

\section{Amount of waste-Technological changes}

The amount of radioactive waste resulting from decommissioning can vary significantly from different sites and reactor technologies. Considering the IRIS case the reactor vessel can act as a sarcophagus for the reactor internals, (i.e., the irradiated internals, minus the fuel, can be left inside the vessel), thus greatly simplifying decommissioning and transportation. The reflector reduces neutron leakage; it significantly reduces the fast neutron fluence on the reactor vessel, as well as the dose outside the vessel to the extent of yielding, for any practical purposes, a "cold" vessel. This has obvious beneficial impacts on decommissioning costs. The IRIS configuration provides sufficient gamma shielding to limit the dose outside the vessel from activated internals (barrel, lower support plate) to make it easier and more economical to perform periodic in-service inspections and final decommissioning and disposal $[20,21]$. This cost driver has been quantified in chapter 4.2.

\section{Decommissioning strategy options}

The decommissioning strategies can be divided in the "immediate decommissioning" or "deferred decommissioning - safe enclosure". The "immediate decommissioning" strategy has a specific cost $[\$ / \mathrm{KWe}]$ much greater than "deferred decommissioning" (for all the details see [3]). Since the technical saving has been calculate as percentage of the total cost by changing the strategy options the saving slight change. This has been highlighted in chapter 4.2.

\section{Operating history}

The operating history of a reactor has an impact on decommissioning. Fuel leakage and water chemistry events as well as the reactor operating load factor during its lifetime impacts on the decommissioning costs. Moreover, some plants have undergone refurbishment or replacement programmers during their lifetime. This may have resulted in more materials contaminated with radioactive substances being stored on the site, e.g. redundant heat exchangers, which then have to be included within the decommissioning plans, increasing the overall costs.

The new design solutions embedded in the modern SMR should reduce (or even eliminate) the cost related to the leakage and accident in general. Carelli et al. [22] show how using the "safety by design approach" it is possible to drastically reduce the probability of having an accident. The IRIS reactor reduces the probability of Loss of Coolant Accident (LOCA) since no large primary penetrations of the reactor vessel or large loop piping exist; this is the most visible safety potential characteristic of integral reactors. This approach is common to other SMR as exposed by Mynatt [23]. However comparing the new SMR to new GEN III+ passive reactor (such as AP1000 or ESBWR) the estimation of this cost driver can be very speculative. Therefore, being conservative, for a SMR this driver not included in the analysis. Moreover the impact of this driver is much smaller than the previous ones: almost all the references divide the decommissioning cost only according to the decommissioning strategy options and the type of reactor.

\section{Type of reactor}

Depending on the Reactor technology (PWR, BWR, GCR, HWR etc.) there is a different specific cost $[\$ / \mathrm{KWe}$. However the analysis compares two reactors based in the same technology, i.e. either PWR or BWR, so for a differential analysis this factor is not considered even if has been included in the regression analysis (see chapter 4)

\section{Site re-use}

The assumptions on the reuse of the site at the end of decommissioning can vary and affect the extent of required decommissioning, (so the related costs). Since the model assumes the same Site re-use this driver is computed as not differential. 
Scope of decommissioning activities

The scope of decommissioning, (including the assumed starting point and end point of decommissioning) impact on decommissioning costs. Since the research assumes the same project scope this driver is not differential.

\section{Clearance and classification levels}

The allowable clearance levels at which materials can be categorized as non-radioactive vary from country to country. This has an impact on the quantity of material resulting from decommissioning that will need to be classified as radioactive waste. Since the model compares the cost in the same country this driver is not differential.

\section{Regulatory standards}

Regulatory standards that could affect decommissioning activities and costs vary from country to country, however since the model compares the cost in the same country this driver is not differential.

\section{Availability of radioactive waste repositories}

The assumed design and location of repositories varies as well as the acceptance criteria, this has in impact on costs. Since the model compares the cost assuming the same availability of radioactive waste repositories this driver is not differential.

\section{Uncertainties and uncertainty treatment}

This driver deals with the Uncertainties connected to the decommissioning process. Comparing two new design (as IRIS vs. AP1000 or CCR vs. ESBWR) it is reasonable to assume the same level of uncertainties about the decommissioning cost, therefore this driver is not differential.

\section{Labour costs}

Decommissioning can be a labour intensive activity and labour costs may be a significant component of total decommissioning costs, however since the model compares the cost in the same country this driver is not differential.

\section{Social and political factors}

Social and political factors need to be taken into account and can have a significant impact on decommissioning strategy, plans and hence costs, however since the model compares the cost in the same country this driver is not differential.

\begin{tabular}{|c|c|c|}
\hline Cost Driver & Differential & Quantified \\
\hline $\begin{array}{c}\text { Size of reactor } \\
\text { site }\end{array}$ & Yes & Yes \\
\hline $\begin{array}{c}\text { Amount of Waste - } \\
\text { Technological changes }\end{array}$ & Yes & Yes \\
\hline $\begin{array}{c}\text { Decommissioning strategy } \\
\text { options }\end{array}$ & Yes & Yes \\
\hline Operating History & Maybe & No \\
\hline Type of reactor & No & No \\
\hline Site re-use & No & No \\
\hline $\begin{array}{c}\text { Scope of decommissioning } \\
\text { activities }\end{array}$ & No & No \\
\hline $\begin{array}{c}\text { Clarence and classification } \\
\text { level }\end{array}$ & No & No \\
\hline Regulatory Standard & No & No \\
\hline $\begin{array}{c}\text { Availability of radioactive } \\
\text { waste repositories }\end{array}$ & No & No \\
\hline $\begin{array}{c}\text { Uncertainties and } \\
\text { uncertainty of treatment }\end{array}$ & No & No \\
\hline Labour Cost & No & No \\
\hline Social and Political Factor & No & No \\
\hline
\end{tabular}

Table 3 Cost drivers for decommissioning

\section{Results}

\subsection{Economy of scale and Multiple units in a single site}

The NEA [3] provides 53 decommissioning cost data by 24 countries. The data set covers different reactor types with sizes ranging from less than $10 \mathrm{MWe}$ to 1350MWe. The reactor types considered are PWR WWER, BWR, CANDU, GCR, and RBMK. Since the model aims to compares LWR the data set has been restricted to PWR WWER, BWR reactors excluding CANDU, GCR, and RBMK. Considering that the scope is to compare commercial reactor the size range has been reduced to 58-1350 MWe. By analysing the Figure 2 seems that the economy of scale is strong when there is just one reactor and weak in case of 2 reactors. This conclusion could be misleading since, as exposed in Figure 3, the low cost of some decommissioning project is due to the location of the reactor in a non OECD ${ }^{1}$ country where the labour cost is lower and reactors typically share the site.

In order to avoid this kind of misleading interpretation a Multiple Regression Analysis (MRA) has been used. MRA is a powerful tool able to handle this kind of problems and exactly quantify the impact of each cost driver since allows a deep exam of the trend correlation between the dependent and the explanatory variables.

1 Organisation for Economic Co-operation and Development. In the MRA the OECD countries are only the founding countries 


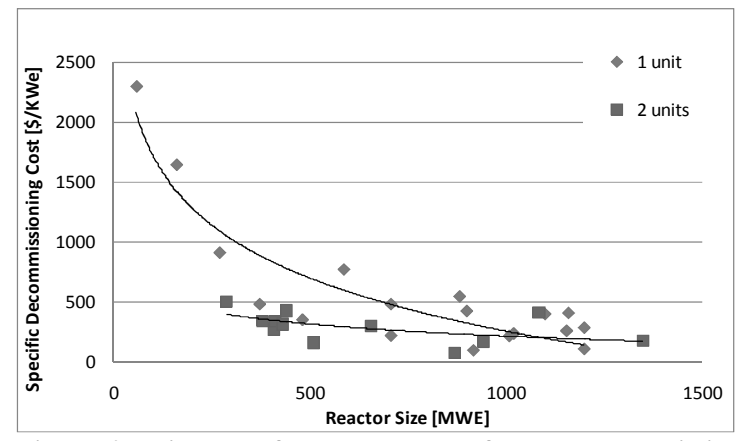

Figure 2 Evidence of the Economy of scale and co-sitting saving. Elaboration from [3]

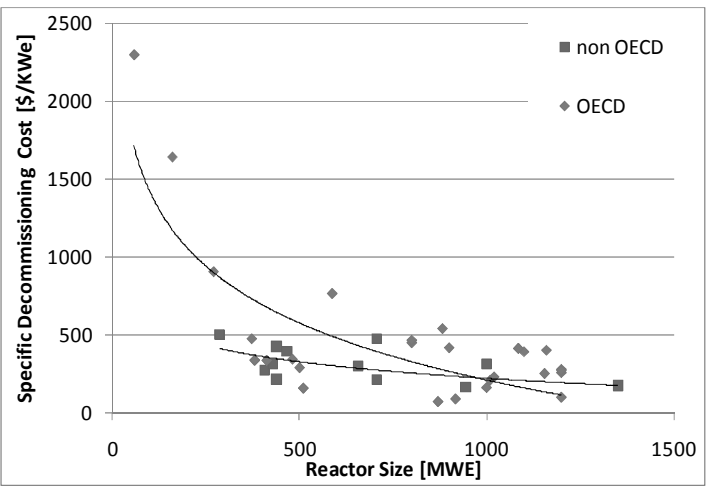

Figure 3 Influence of sitting. Elaboration from [3]

\section{Size of reactor}

The MRA shows a value for the economy of scale equal to 3.09 i.e. if the size is reduced from $1340 \mathrm{MWe}$ to $335 \mathrm{MWe}$ the specific decommissioning cost [\$/KWe] becomes 3 time higher (as is possible to understand from Figure 2). This is due to the fact that many cost elements in the decommissioning cost (as exposed by $[8,14]$ ) are independent from the size or the dependency is very weak.

\section{Number of units on the site}

When more units share the same site, there are cositting savings; Figure 2 shows that to decommission 2 units has specific cost smaller than decommission just one reactor. The MRA has been carried out with a database [3] mainly composed by stand alone reactor or site composed by two reactors. Therefore it is not correct to compute a value for four reactors directly from the MRA. On the other hand the MRA can correctly provide the estimation for a site composed by one of two reactors. The decommissioning cost of two reactors in the same site is less than double of two reactors in two sites because there are not recursive costs (i.e. fixed costs). Therefore the cost of the second unit can be assumed as a "marginal cost", i.e. the sum of the variable cost to decommission a further unit.

The model assumes that the cost of the third and fourth units is the same of the second one (i.e. assumes the same marginal cost).
Therefore the first step is to compare a site with 11340 MWe reactor vs. the same site with $2335 \mathrm{MWe}$. In this case the specific cost ratio

$$
\frac{\text { One large Plant Specific cost }}{\text { Two small Plant Specific cost }}
$$

is 2.63. Therefore the second units have a "specific cost" equal to 2.16 because $\frac{3.09+2.16}{2}=2.63$. Assuming the same marginal cost for the units number 3 and 4 it is possible to compute the value "smaller than one" for the multiple units driver.

This value calculated as:

first unit cost $+3 \times$ second unit cost $4 \times$ first unit cost

[eq. 1]

is equal to 0.78 . The meaning of this value is: there is a specific cost saving equal to $22 \%$ in decommissioning 4 units instead of 1 . This is can be a conservative value since the third and forth units, with a suitable decommissioning schedule, can achieve a strong advantage from learning [24, 25]. However, since is difficult to foreseen the decommissioning schedule even before the constructions start, the assumption that the cost of the third and forth units has the same order of magnitude that the second one seems the most realistic.

\subsection{Technical Saving}

Dominion [17], points out as the "technology" incorporated into the design and construction of the advanced reactors should facilitate decommissioning. Design features that minimize working area radiation levels or contamination levels can reduce the effort and cost to ultimately remediate components and structural surfaces. The Sustainable development commission [26] shows that the reduction of components (with emphasis with radioactive components) can lead to a cost saving in the decommissioning phase. Therefore these references are consistent with the assumptions behind the Amount of waste driver (see chapter 3.).

To quantify this advantage the methodology compares the decommissioning cost of a standard WWER-440 reactor with a SMR with the innovative passive feature (Like IRIS that for now on will be used for the comparison). Having reduced the size with the economy of scale the model compares now a reactor with the same design of a Large One (as the WWER440) with an innovative SMR passive reactor.

Here the idea is to adjust the Standardised cost items for a WWER decommissioning projects, provided by Pittiglio [16] with the specific features of IRIS reactor and then to compute the ratio. Thanks to the safety 
features and the integral design the amount of waste produced by an IRIS decommission project is lower $[20,21]$. By elicitation of experts the model reduce the value of some specific account of the cost list (in particular the sub-account inside, 04 Dismantling activities and 05 Waste processing, storage and disposal) computing the average "IRIS decommissioning $\operatorname{cost}^{2}$ ",

The technical saving factor is computed as:

SMR decommissioning cost

WWER 440 decommissioning cost

\section{Decommissioning strategies}

Even if "Immediate Decommissioning" and "Deferred Decommissioning" have the same Cost Breakdown Structure (CBS) the cost of some Work Package (WP) is different. This is mainly due to the different toxicity of the material in the decommissioning activity. The immediate decommissioning activity presents a higher cost than deferred decommissionig due to the larger amount of toxic material. Therefore since the reduction of toxic material is one of the key advantages of the SMR technology it is clear that in the first case the SMR has a greater competitive advantage. In order to identify the technological saving factor in both the cases the methodology here presented is implemented in the two next paragraphs.

\section{Immediate Decommissioning}

Immediate Decommissioning is the method in which the equipment, structures, and portions of a facility and site containing radioactive contaminants are removed or decontaminated to a level that permits the property to be released for use shortly after cessation of operations [17].

Figure 4 provides the breakdown cost for the Immediate decommissioning option.

Here Dismantling activities and Waste processing, storage and disposal account for half of the total cost and

$$
\frac{\text { IRIS decommissioning cost }}{\text { WWER } 440 \text { decommissioning cost }}=0.81
$$

The cost saving due to the technology improvement is $19 \%$.

\footnotetext{
${ }^{2}$ The weak economy of scale and multiple units saving are not considered, i.e. the model compare an WWER with an "440 MWe IRIS"
}

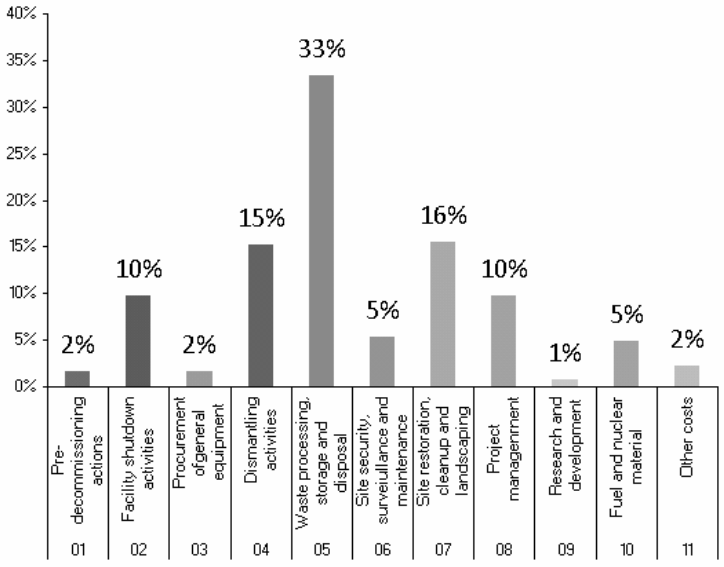

Figure 4 Immediate decommissioning breakdown cost. Elaboration from [15]

\section{Deferred Decommissioning}

Deferred Decommissioning is the method in which the nuclear facility is placed and maintained in a condition that allows the nuclear facility to be safely stored and subsequently decontaminated (deferred decontamination) to levels that permit release of the property [17]. The time between the shout down and the dismantling activities can be of some decades.

Figure 5 provides the breakdown cost for the deferred decommissioning option. Here Dismantling activities and Waste processing, storage and disposal account for $45 \%$ of the total cost, with a drastic reduction of the Waste processing storage and disposal cost. Since the technology improvement tends to reduce this cost there is, for this option, a smaller margin of saving.

The approach correctly quantifies this aspect in fact

$$
\frac{\text { IRIS decommissioning cost }}{\text { WWER } 440 \text { decommissioning cost }}=0.87
$$

The cost saving due to the technology improvement is $13 \%$

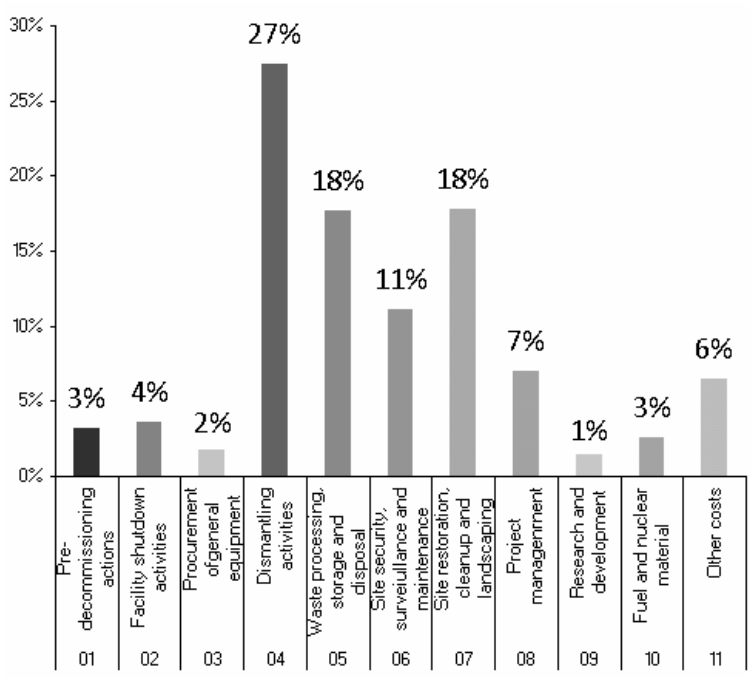

Figure 5 Deferred decommissioning breakdown cost. Elaboration from [15] 


\subsection{Final Results}

In this research two sets of two variables has been evaluated:

1. $1 \mathrm{LR}$ or $2 \mathrm{LR}$ vs. $4 \mathrm{SMR}$ or $8 \mathrm{SMR}$

2. Immediate or deferred decommissioning

This take to the analysis of four scenarios.

In Table 4 the scenario of 4 SMRs Vs. 1 LR and Immediate Decommissioning has been analyzed. This table points out as just considering the economies of scale the specific cost of an SMR should be 3.09 times higher than a LR, however when 4 units are considered there is a relative saving and the cost becomes 2.42 time higher (3.09 $\mathrm{x}$ 0.78). Moreover when the technology advantage is included in the analysis there is a further reduction of the gap which becomes, at the end $1.96(2.42 \mathrm{x}$ 0.81). Therefore the final decommissioning cost of a site with 4 SMR is double than a site with 1 LR. Also for Deferred Decommissioning (Table 5) when the various factors are combined, a pack of four 335 MWe SMRs has a decommissioning cost double than the monolithic 1340 MWe reactor.

A case of eight IRIS and two large plants on site, (Table 6 and Table 7), reflecting the proportionally higher effect of two large units on site, leads to a smaller multiple units differential saving.

The cost ratio increases to 2.21 and 2.35 for Immediate Decommissioning and Deferred Decommissioning respectively. Obviously this evaluation is necessarily approximate and only four factors were considered, but it can be concluded that the decommissioning cost of an SMR pack is quite higher than a single large plant.

\begin{tabular}{lcc}
\hline \multicolumn{1}{c}{ Factor } & $\begin{array}{c}\text { Individual } \\
\text { SMR/Large }\end{array}$ & $\begin{array}{c}\text { Cumulative } \\
\text { SMR/Large }\end{array}$ \\
\hline (1) Economy of scale & 3.09 & 3.09 \\
(2) Multiple units & 0.78 & 2.42 \\
(3) Technical Saving & 0.81 & $\mathbf{1 . 9 6}$ \\
\hline
\end{tabular}

Note: SMR is one 335 MWe plant, as part of four units. Large is one single 1340 MWe plant.

Table 4 Quantification of factors evaluated in 4 SMRs Vs. 1 Large plant comparison. Immediate Decommissioning

\begin{tabular}{lcc}
\hline \multicolumn{1}{c}{ Factor } & $\begin{array}{c}\text { Individual } \\
\text { SMR/Large }\end{array}$ & $\begin{array}{c}\text { Cumulative } \\
\text { SMR/Large }\end{array}$ \\
\hline (1) Economy of scale & 3.09 & 3.09 \\
(2) Multiple units & 0.78 & 2.42 \\
(3) Technical Saving & 0.87 & $\mathbf{2 . 0 9}$ \\
\hline
\end{tabular}

Table 5 Quantification of factors evaluated in 4 SMRs Vs. 1 Large plant comparison. Deferred Decommissioning

\begin{tabular}{lcc}
\hline \multicolumn{1}{c}{ Factor } & $\begin{array}{c}\text { Individual } \\
\text { SMR/Large }\end{array}$ & $\begin{array}{c}\text { Cumulative } \\
\text { SMR/Large }\end{array}$ \\
\hline (1) Economy of scale & 3.09 & 3.09 \\
(2) Multiple units & 0.88 & 2.71 \\
(3) Technical Saving & 0.81 & $\mathbf{2 . 2 1}$ \\
\hline
\end{tabular}

Table 6 Quantification of factors evaluated in 8 SMRs Vs. 2 Large plant comparison. Immediate Decommissioning

\begin{tabular}{lcc}
\hline \multicolumn{1}{c}{ Factor } & $\begin{array}{c}\text { Individual } \\
\text { SMR/Large }\end{array}$ & $\begin{array}{c}\text { Cumulative } \\
\text { SMR/Large }\end{array}$ \\
\hline (1) Economy of scale & 3.09 & 3.09 \\
(2) Multiple units & 0.88 & 2.71 \\
(3) Technical Saving & 0.87 & $\mathbf{2 . 3 5}$ \\
\hline
\end{tabular}

Table 7 Quantification of factors evaluated in 8 SMRs Vs. 2 Large plant comparison. Deferred Decommissioning

\section{Conclusions}

The target of this study was to determine the differential factors for the comparison of SMRs and Large Reactors on decommissioning. Some findings came out: if the economy of scale is the unique driver for decommissioning cost estimation Small Modular Reactors are absolutely not competitive (because the value is 3 time higher), but there are evidences of other key factors able to reduce the gap between the two classes of reactors. Considering these factors (site sharing and different technology solutions) the specific decommissioning cost [\$/MWe] of an SMR is almost double respect to a Large Reactor

If more than 1 Large Reactor is considered the gap increases since also the Large Reactor investment reaps advantages from site sharing. Therefore the target market for SMR is composed by site with a global size of 1 or $1.5 \mathrm{GW}$. Beside these considerations it is necessary to highlight as the Decommissioning cost account weights for just few percents of the total cost, therefore the investors has to carefully evaluate the incidence of this value among the overall benefits of this class of reactors on the the entire life cycle. 


\section{References}

[01] Carelli M.D., Mycoff C.W., Garrone P. Locatelli G., Mancini M, Ricotti M.E., Trianni A., and Trucco P, 2008. "Competitiveness of SmallMedium, new generation Reactors: a comparative study on Capital and O\&M Costs", Proceedings of the 16th International Conference on Nuclear Engineering ICONE16 May 11-15, 2008, Orlando, Florida, USA, Paper 48931.

[02] IAEA, 2007, "Safety glossary-Terminology used in nuclear safety and radiation protection". 2007 edition, International atomic energy agency, Vienna, Austria.

[03] NEA/OECD, 2003, "Decommissioning Nuclear Power Plants: Policies, Strategies and Costs", Nuclear energy agency / Organisation for economic co-operation and development, France, Paris.

[04] Williams D.G., 2007, "U.S. nuclear plant decommissioning funding adequacy-by individual funds, utilities, reactors, and industrywide-assessed by Monte Carlo and baseline trend methods: 1998, 2000, 2001, and 2004". Energy Economics 29, pp. 1050-1100.

[05] McKeown J., 2003, "Decommissioning. Lessons to learn". IAEA Bulletin 45/1. June 2003, International atomic energy agency, Vienna, Austria.

[06] DOE, 2003, "Assumptions to the Annual Energy Outlook 2003" Department of Energy. Energy Information Administration, Washington, DC 20585.

[07] NEA, 1999, “A proposed standardised list of items for costing purposes in the decommissioning of nuclear installations", Nuclear energy agency / Organisation for economic co-operation and development, France, Paris.

[08] Liu, L. and Zhu, K, 2007, "A Stage-By-Stage Factor Control Framework for Cost Estimation of Construction Projects". ASCE's Journal of Construction Engineering and Management, 133, 1, pp. 91-95.
[09] IAEA, 2005, "Financial aspects of decommissioning”. TECDOC-1476, International atomic energy agency, Vienna, Austria

[10] IAEA, 2000, "Organization and Management for Decommissioning of Large Nuclear Facilities", Technical Reports Series No. 399, International atomic energy agency, Vienna, Austria

[11] IAEA, 2000, "Safety related publications. Predisposal management of radioactive waste, including decommissioning". AEA WS-R-2. International atomic energy agency, Vienna, Austria

[12] IAEA, 2008, "Decommissioning of Research Reactors and Other Small Facilities by Making Optimal Use of Available Resources", Technical Reports Seri Es No. 463, International atomic energy agency, Vienna, Austria

[13] KwanSeong, J., DongGyu, L., ChongHun, J. and KuneWoo, L., 2007, "Structures and elements for the decommissioning Cost estimations of nuclear research reactors", Annals of Nuclear Energy, 34, pp. 326-332.

[14] Manning, R., Gilmour, J., 2002, "Decommissioning Cost Estimating -The "Price" Approach", Proceeding to the Waste Management Symposium, Tucson, AZ, US.

[15] IAEA, 2002, "Decommissioning costs of WWER440 nuclear power plants". TECDOC-1322, International atomic energy agency, Vienna, Austria

[16] Pittiglio, C.L., 2004, "Standard Review Plan for Decommissioning Cost Estimates for Nuclear Power Reactors“ NUREG-1713, U.S. Nuclear Regulatory Commission, Washington, DC.

[17] Dominion Energy Inc., 2004, "Study of Construction Technologies and Schedules, O\&M Staffing and Cost, Decommissioning Costs and Funding Requirements for Advanced Reactor Designs" United States Department of Energy. Cooperative Agreement DE-FC07-03ID14492 Contract DE-AT01-020NE23476, Washington, DC.. 
[18] Nirex, 2005, “Technical note. Summary Note for CoRWM on Cost Estimates for CoRWM Option 7 (Deep Geological Disposal) and Option 9 (Phased Deep Geological Disposal)". Committee on Radioactive Waste Management, London, England

[19] Kuznetsov V., 2008, "Options for small and medium sized reactors (SMRs) to overcome loss of economies of scale and incorporate increased proliferation resistance and energy security". Progress in Nuclear Energy 50, pp. 242e250.

[20] Carelli, M.D., 2003, “ Iris International Reactor Innovative And Secure". U. S. Department of Energy Nuclear Energy Research Initiative Project Number: 99-0027. Research Grant Number: DE-FG03-99SF21901.

[21] Carelli, M.D., 2003, "IRIS: A global approach to nuclear power renaissance". NUCLEA NEWS September 2003, pp 32-42.

[22] Carelli, M.D., Conway, L.E., L. Oriani, L., Petrovi'c, B., Lombardi, C.V., Ricotti, M.E., Barroso, A.C.O., Collado, J.M. , Cinotti, L., Todreas, N.E., Grgi'c, D., Moraes, M.M., Boroughs, R.D., Ninokata, H., Ingersoll D.T. and Oriolo, F., 2004, “The design and safety features of the IRIS reactor", Nuclear Engineering and Design 230, pp.151-167.

[23] Mynatt F.R., 2003, “Design and layout concepts for compact, factory-produced, transportable, generation IV reactor systems". Nuclear Energy Research Initiative (NERI) program. Grant number DE-FG07-00SF22168.

[24] CORWM, 2006, Committee on Radioactive Waste Management, "Managing our radioactive waste safely". Committee on Radioactive Waste Management, London, England

[25] IAEA, 2004, "Planning, managing and organizing the decommissioning of nuclear facilities: lessons learned" IAEA-TECDOC-1394, International atomic energy agency, Vienna, Austria

[26] Sustainable development commission, 2006. "The role of nuclear power in a low carbon economy.

Paper 5. Waste and decommissioning" 